TITLE:

\title{
$<$ Note> A Chimpanzee Trifling with a Squirrel: Pleasure Derived from Teasing?
}

$\operatorname{AUTHOR}(S):$

Zamma, Koichiro

CITATION:

Zamma, Koichiro. <Note> A Chimpanzee Trifling with a Squirrel:

Pleasure Derived from Teasing?. Pan Africa News 2002, 9(1): 9-11

ISSUE DATE:

2002-06

URL:

http://hdl.handle.net/2433/143404

RIGHT:

Copyright (C) Pan Africa News. 


\section{$<\mathrm{NOTE}>$ \\ A Chimpanzee Trifling with a Squirrel: Pleasure Derived from Teasing?}

\section{Koichiro Zamma}

\section{Graduate School of Science, Kyoto University}

This paper reports a rare observation of a chimpanzee (Pan troglodytes schweinfurthil) killing a squirrel (Heliosciurus rufobrachium) but not eating it. This observation was made at Mahale Mountains National Park, Tanzania.

On J une 27, 2000, at 16:35, I observed Nkombo (NK, adult female) walking with three other adult females, Totzy (TZ), J uno, and Xtina, as well as Fanana (adult male), Pipi (adolescent female), J idda (J D, juvenile female) and Xmas (XM, juvenile male). At 16:38, I heard the cries of a squirrel in a bush. I then observed that NK had already captured a squirrel. I videotaped the behavior of NK starting from 16:39 (Table 1, Figure 1). NK swung and shook the squirrel, dragged it along the ground, pressed on it with the back of the wrist, and bit its hand while grasping its tail. The squirrel sometimes tried to escape from NK but was at the mercy of NK most of the time: It was beaten against roots, woody vines and the ground. NK also liberated the squirrel, chased it, rotated it with the back of her wrist, and swung her lower arm in presentation to the squirrel. When the squirrel tried to counterattack against the presented arm, NK looked for a chance to take its tail between her teeth with a play face (Figure 2). NK sometimes threw the animal by her mouth or by her hand and also hit it with the back of her wrist.

At 16:44, NK pressed on the squirrel with the palm of her left hand against the ground. The squirrel emitted its last loud cry. At 16:44, NK pressed on it with the palms of both hands. The squirrel had a convulsion, which was its last movement.

After the squirrel was killed, NK pressed on its carcass with the palms of both hands again against the ground and bit it. NK also held its body with her left hand and plucked its hairs with her teeth. At 16:45, NK left there holding the body of the carcass with her left hand. At 16:46, NK shook it by holding its tail with her mouth. She pressed on the carcass with the palms of her hands again against the ground and bit it. Then, NK threw the carcass with her mouth, and left there without holding the carcass. This behavior of NK occurred on the ground from start to end.

(a) When the squirrel was alive (16:39 - 16:45).

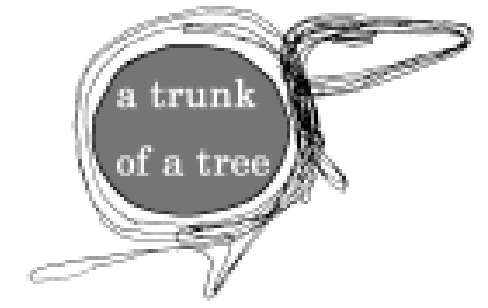

(b) After the squirrel died (16:45 - 16:46).

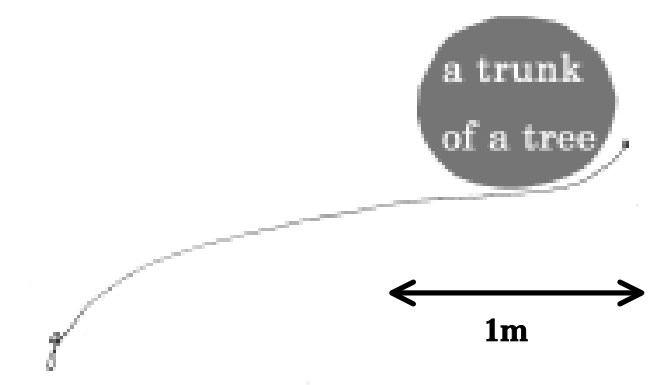

Figure 1. The place used by NK when the squirrel was alive (a) and after the squirrel died. 
The other chimpanzees, except for XM, paid little attention to the squirrel and NK. Kalunde (adult male) and J D just watched the squirrel and NK at a distance of more than $1 \mathrm{~m}$ and left there after staying for 4 minutes and 1 minute, respectively. TZ stayed there for 4 minutes, peered and waved her lower arm to the squirrel grasped by NK. XM stayed there and watched the entire period of this behavior by NK. While the squirrel was alive (16:39-16:45), XM spent the most time watching the squirrel and NK at a distance of more than $1 \mathrm{~m}$. XM sometimes approached the squirrel, stamped bipedal, swept fallen leaves with his both hands, peered at the squirrel, and poked it quickly. After the squirrel died, XM swept fallen leaves with his hand and watched NK and the carcass. After NK stopped handling the carcass, XM approached it, peered at it, swept fallen leaves with his hand, and pulled its tail. After NK left there, XM swayed a woody vine near the carcass, and peered at it. At 16:46, XM departed and followed NK.

The weight of the squirrel was $298 \mathrm{~g}$, the length of head and body was $24 \mathrm{~cm}$, and the length of tail was $27 \mathrm{~cm}$. The squirrel had no conspicuous external wound except for its tail, which was peeled while it was still alive.

Neither NK nor XM ate the squirrel, though there have been seven reports that chimpanzees hunted and ate squirrels (e.g. 1, 2) in Mahale. It was unknown why no chimpanzees ate it.

There were movements that seemed to involve hunting and/or play in the behavior of NK: Grabbing, chasing, pulling, throwing, swinging and beating a prey against roots and biting have been observed in hunting; throwing, pulling and rotating objects have been observed in lone play; and biting, chasing, pulling and making a play face have been observed in social play (3).

Swinging her lower arm in presentation to the squirrel was a unique movement that has not been observed so far. NK used her arm as a decoy to distract the attention of the squirrel. While the squirrel tried to jump and bite NK, she watched for a chance to take its tail and succeed in biting

Table 1. The duration of the movements of NK and the behavior of the squirrel.

\begin{tabular}{|c|c|c|c|c|}
\hline & $\begin{array}{c}\text { body part of the } \\
\text { squirrel held by NK }\end{array}$ & no. of bouts & total duration (s) & $\begin{array}{c}\text { behavior of } \\
\text { the squirrel * }\end{array}$ \\
\hline \multicolumn{5}{|l|}{ When the squirrel was alive (16:39-16:45) } \\
\hline rest & tail & 6 & 47 & $n, e, b, c$ \\
\hline swing it & tail & 4 & 44 & $n, c$ \\
\hline pull it along the ground & tail & 12 & 123 & $n, e, c$ \\
\hline bite or try to bite & no, tail & 5 & 13 & $n, e, c$, \\
\hline throw & tail & 5 & 6 & $\mathrm{n}, \mathrm{e}, \mathrm{c}$ \\
\hline stamp & tail & 2 & 3 & $n, b, c$ \\
\hline rotate it with the back of her wrist & no & 2 & 5 & $n, b, c$ \\
\hline swing her lower arm in presentation to it & no & 5 & 25 & $e, b, c$ \\
\hline chase it & no & 5 & 19 & $\mathrm{e}, \mathrm{c}$ \\
\hline hit it with the back of her wrist. & no & 1 & 4 & b, c \\
\hline press on it with the back of her wrist & tail & 1 & 4 & $\mathrm{n}$ \\
\hline press on it with the palms of her hands & no & 2 & 8 & $c, v$ \\
\hline not observed & - & - & 36 & - \\
\hline \multicolumn{5}{|l|}{ After the squirrel died (16:45-16:46) } \\
\hline rest with it & body & 2 & 16 & $\mathrm{n}$ \\
\hline rest without it & no & 1 & 24 & $\mathrm{n}$ \\
\hline press on it with the palms of her hands and bite it & no & 2 & 14 & $\mathrm{n}$ \\
\hline pluck its hairs with her teeth & body & 1 & 7 & $\mathrm{n}$ \\
\hline move & body & 1 & 6 & $\mathrm{n}$ \\
\hline shake & tail & 1 & 1 & $\mathrm{n}$ \\
\hline throw & body & 1 & 1 & $\mathrm{n}$ \\
\hline not observed & - & - & 25 & - \\
\hline
\end{tabular}

* n: nothing, e: try to escape from NK, b: try to bite or jump (counterattack), c: cry, v: convulsion. 


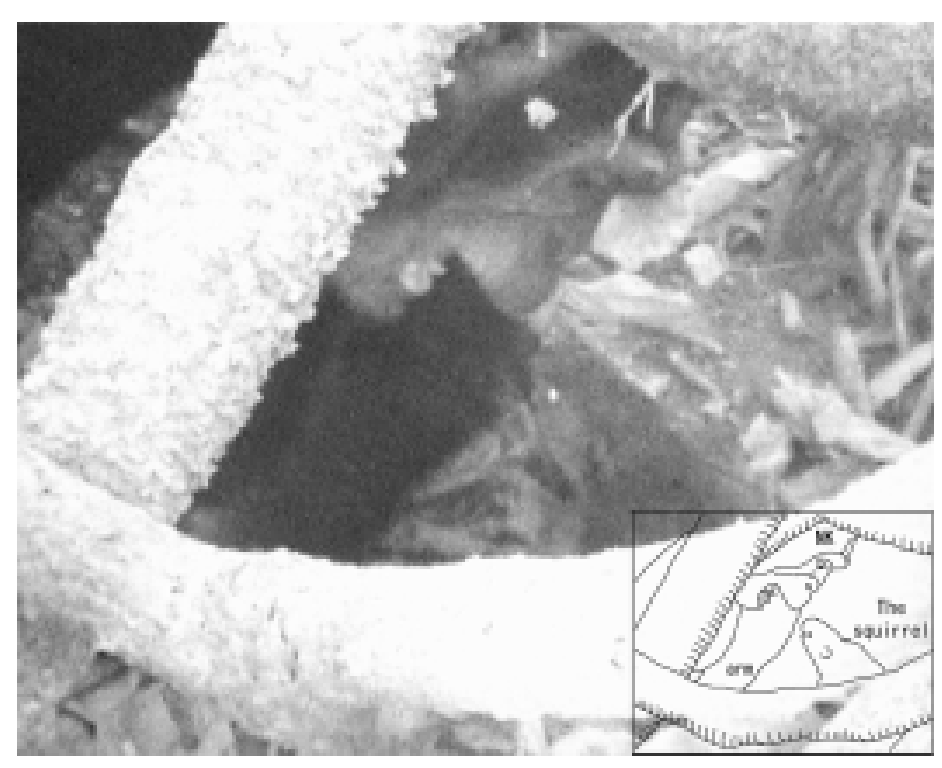

Figure 2. NK was watching the squirrel with a play face.

it. It looked like a bullfight: NK as a matador waved a red cloth (her lower arm) in front of a bull (a squirrel), and stabbed (bit) it. This movement seemed like a kind of social play having the characteristic of teasing because NK allowed the squirrel to counterattack and NK showed a play face. Similarly, when western chimpanzees captured and toyed with a hyrax (Dendrohyrax dorsalis) at Bossou, Guinea, swinging the hyrax in the air, beating it against branches, and making a play face were also observed while the object was alive (4). Pleasure derived from teasing a playmate has also been reported. (3, p. 175).

The behavior of NK was different between when the squirrel was alive and after it died. The body part of the squirrel that NK grasped changed from its tail to its body. This seemed to show that NK realized that a counterattack by the squirrel was no longer possible. The place where NK played with the squirrel also changed because she could not play with it in the same way as when it was alive. NK tried to play it more, but it continued only a minute. This case is helpful in understanding the recognition of death by chimpanzees.

\section{References}

(1) Hosaka K, Nishida T, Hamai M,
Matsumoto-Oda A, Uehara S 2001. Predation of Mammals by the chimpanzees of the Mahale Mountains, Tanzania. In: All apes great and small, Vol. 1: African Apes. Galdikas BMF, Briggs NE, Sheeran LK, Shapiro GL, Goodall J (eds), Kluwer Academic Publishers, New York. pp. 107-130.

(2) Huffman MA, Kalunde MS 1993. Tool-assisted predation on a squirrel by a female chimpanzee in the Mahale Mountains, Tanzania. Primates 34: 93-98.

(3) Nishida T, Kano T, Goodall J , McGrew WC, Nakamura M 1999. Ethogram and ethnography of Mahale chimpanzees. Anthropological Science 107: 141-188.

(4) Hirata S, Yamakoshi G, Fujita S, Ohashi G, Matsuzawa T 2001. Capturing and toying with Hyrazes (Dendrohyrax dorsalis) by wild chimpanzees ( $P$ an troglodytes verus) at Bossou, Guinea. Amer. J. Primatol. 53: 93-97. 